\title{
Christian Laval y Pierre Dardot, Común. Ensayo sobre la revolución en el siglo XXI, Barcelona, Gedisa, 2015, 672 pp.
}

Perfiles Latinoamericanos, 26(51)

2018 | pp. 409-417

DOI: $10.18504 / \mathrm{pl} 2651-017-2018$

L

noción de lo común ha pasado por distintas reelaboraciones durante las últimas décadas a partir de la convergencia de discursos y teorías de múltiples disciplinas académicas, movimientos sociales y activismos que evidencian la univocidad e insuficiencia de la dicotomía público/privado. Estos planteamientos coinciden en un argumento central: la privatización y el cerco progresivo de esferas fundamentales para la vida supone un gran riesgo para la humanidad y, en consecuencia, es necesario instituir una racionalidad que se rija por criterios diferentes a los del mercado. Este es el asunto que aborda Común. Ensayo sobre la revolución en el siglo XXI problematizando la captura del término por los comunismos de Estado y rescatando su importancia para pensar en la posibilidad de otro modelo económico y social. En su anterior libro, Laval y Dardot ${ }^{1}$ explicaban que el neoliberalismo no es un modelo económico sino una racionalidad que abarca cada vez más áreas de la vida, estrechando el marco de posibilidades en el que nos movemos. Para construir una alternativa se requiere pensar en nuevas formas de vida. No se puede combatir esta gubernamentalidad sin otro imaginario y sin antes responder a la pregunta de cuáles son las formas de vida deseables. Común, escrito dos años después, supone el intento de responderla. Los autores estuvieron atentos a los movimientos sociales que surgieron en todo el mundo como el 15M de España en 2011 o las protestas y ocupación de la plaza Taksim de Estambul en 2013. Lavat y Dardot encontraron una

1 Laval, C. \& Dardot, P. (2013). La nueva razón del mundo. Ensayo sobre la sociedad neoliberal. Barcelona: Gedisa. 
hebra que unía las motivaciones de los diferentes movimientos de indignados: la experimentación de emergentes formas de vida en la ocupación de las plazas y la reivindicación de lo público. Una pancarta con las palabras "Comuna de Taksim" evocaba en Estambul la experiencia de la comuna de París y evidenciaba la demanda por una democracia en su sentido más radical. La referencia a estos movimientos sociales, sin embargo, ocupa pocas páginas del libro, que no es un estudio sobre luchas sociales sino un intento de articular y definir lo común como principio político que sirva de referencia teórica y práctica. Ante la amenaza de expolio permanente de bienes y espacios comunes, los autores proponen pensar en un "más allá del capitalismo" y recuerdan, citando a Cornelius Castoriadis, que esto solo será posible "cuando una reconstrucción ideológica radical se encuentre con un movimiento social real” (p. 20).

El libro de Laval y Dardot contrapone el principio de lo común al de la competencia, que es la forma de vida privilegiada de la razón neoliberal. El derecho absoluto de propiedad, cuyo principal argumento de defensa es la preservación de la vida, es cuestionado por los autores cuando afirman que es justamente el absolutismo de la propiedad el que se constituye en una amenaza para la humanidad y el planeta. Lo público estatal y lo privado se desvelan no solo como incapaces de ofrecer soluciones a los problemas actuales sino como cómplices y responsables de los procesos de apropiación, de desigualdad y de deterioro de recursos. El cercamiento progresivo de todas las áreas de la vida está expresado en la transferencia de bienes públicos a los privados, en la extensión de la mercantilización y la propiedad privada a través de patentes y propiedad intelectual sobre lo viviente (semillas, plantas, genoma humano); en la privatización e introducción de criterios de rentabilidad en los sistemas de educación, salud y pensiones; o en la especulación financiera e inmobiliaria. Estas nuevas olas de apropiación de riqueza que tienen lugar por la acción del Estado y de multinacionales están justificadas con discursos técnicos y económicos de rendimiento, de efectividad e incluso de transparencia; no obstante, son la causa de los crecientes niveles de desigualdad social y acumulación de recursos en pocas manos. En consecuencia, "protestar contra la enclosure de los comunes significa reanudar la crítica de la propiedad privada como condición absoluta de la riqueza social” (p. 127).

Laval y Dardot identifican bajo lo común el principio político fundamental de convergencia de movimientos sociales en contra del neoliberalismo y sus lógicas de acumulación, privatización y cercamientos. Al plantear que ciertos bienes, recursos y espacios deben ser comunes y cuestionar el derecho absoluto de propiedad, es posible establecer conexiones entre diferentes luchas sociales que cuestionan políticas globales/locales validadoras del aprisonamiento de lo común en todas sus manifestaciones: lo genético, las semillas, el agua, la información, la biodiversidad, los sistemas de alimentación, la neutralidad del Internet, 
la educación, los medios de comunicación, entre otras. Lo que reivindican estos movimientos sociales es el uso común de recursos y espacios tangibles e intangibles. Vandana Shiva afirma que "recuperar los comunes es el deber político, económico y ecológico de nuestra época" (p. 110); Peter Linebaugh, mediante una analogía, relaciona la historia de la destrucción de los comunes en Inglaterra con la coyuntura neoliberal y los movimientos sociales contemporáneos; Naomi Klein define diferentes luchas bajo la defensa de los comunes; Phillippe Aigrain promueve una coalición de bienes comunes que agrupa luchas de bienes ambientales e informacionales. A partir de estas referencias cobran valor palabras como interdependencia, coalición o articulación para denotar que no se trata de luchas aisladas sino de prácticas contemporáneas unidas y conectadas por un hilo común. De esta manera, reivindicaciones que aparentemente no tienen relación se enlazan en una narrativa capaz de oponerse a los postulados neoliberales.

Esta concatenación de estudios diversos tiene uno de sus más importantes antecedentes en el trabajo de la Premio Nobel de Economía Elinor Ostrom, quien marcó un hito en la reflexión sobre lo común con su publicación Governing the Commons en 1990. La autora recopiló allí varios estudios de caso sobre la gestión colectiva de bienes comunes (bosques, sistemas de riego, pesquerías) y planteó que bajo ciertas condiciones eran mejor gobernados por las comunidades que por el Estado y el mercado. Mostró que no había fundamento científico en las políticas públicas que recomendaban la privatización o estatización como única vía de buena administración, con la falsa creencia de que si el trabajo estaba a cargo de las comunidades, sobreexplotarían y agotarían los recursos. Por el contrario, sus investigaciones evidenciaron que estos bienes comunes pueden ser gestionados de forma exitosa por comunidades que coproducen juntas las reglas de uso, para lo que retomó teorías de acción colectiva y de autogobierno. Laval y Dardot reconocen el importante aporte de Ostrom, sin embargo, dan un giro a esta concepción de la economía política. Al postular que ciertas esferas deben ser inapropiables, se preguntan si la noción de bienes comunes, que responde a una tradición neoclásica que escinde lo económico y lo político, es la más adecuada en esta construcción. Los bienes proporcionan un marco de interpretación restringido a la lógica del mercado; al igual que las mercancías, pueden ser comprados, vendidos o poseídos. Laval y Dardot, en cambio, proponen un tránsito de la categoría bienes comunes a la de comunes que definen como "objetos de naturaleza muy diversa de los que se ocupa la actividad colectiva de los individuos" (p. 25). Los comunes autorizan un uso político y reivindicativo más amplio al comprender todo aquello que las comunidades consideren como fundamental para la vida y que no debe ser privatizado o convertirse en objeto de lucro.

La propuesta de Laval y Dardot abre un camino para la investigación de temas filosóficos, jurídicos, económicos, políticos e interdisciplinarios sobre 
lo común a partir de una relectura de las prácticas sociales que se oponen a la privatización de todas las esferas de la vida. En América Latina, una teoría de lo común contribuye al análisis transversal de diversas luchas sociales que defienden la tierra en Brasil, los municipios libres de minería en Colombia, el agua en Cochabamba, la gratuidad de la educación en Chile o las fábricas autogestionadas en Argentina, por mencionar solo algunas. Al conceptualizar estas reivindicaciones como comunes es posible conectar las luchas habituales por bienes, espacios y recursos como la tierra o el agua con nuevas luchas por intangibles como el Internet, la información o los medios de comunicación. Al respecto, los autores problematizan el auge del capitalismo cognitivo que usurpa el discurso de lo común creando comunidades de intereses alrededor de proyectos lucrativos en la web facilitando la concentración de capitales. Así, el discurso redentor que ve en el acceso a Internet y a la información un sinónimo de cambio social o político solo reproduce las dinámicas de concentración: "es en términos de una batalla que atraviesa todo el campo de las nuevas tecnologías como hay que abordar la cuestión de los comunes del conocimiento, rechazando todo profetismo que quiera ver en la tecnología digital el advenimiento inexorable de una sociedad libre" (p. 212). En ese sentido, los autores se alejan de cualquier espontaneidad que pretenda generar cambios sin la necesidad de instituirlos de manera conjunta. Cuestionan las conclusiones de Hardt y Negri en Imperio, Multitud y Commonwealth donde argumentan que lo común podría surgir de forma espontánea a través de una comunidad reticular operando bajo principios de código abierto, de la que pueda esperarse la superación del capitalismo y el surgimiento de un comunismo informacional a través de las posibilidades del Internet y las nuevas tecnologías. Por el contrario, afirman que es mediante la creación de instituciones con reglas coproducidas por parte de las comunidades como puede articularse una propuesta política en la que lo común sea el centro. En este punto coinciden con Elinor Ostrom, quien entendió la administración de lo común a través del establecimiento de instituciones y sistemas que no son impuestos desde arriba sino que responden a las características, particularidades y modos de hacer de las comunidades.

Las principales propuestas de Laval y Dardot se sintetizan en tres postulados que orientan toda su argumentación: 1) Lo común es un principio político que motiva la construcción y resguardo de esferas comunes de las que depende la vida. 2) El núcleo de lo común es un derecho de inapropiabilidad que debe instituirse en oposición al derecho absoluto de propiedad. 3) El autogobierno es un modo de construcción y gestión de lo común a través de prácticas sociales de comunidades comprometidas en la defensa de los comunes. Estas cuestiones se abordan en las tres partes del libro. La primera define lo común, la segunda muestra cómo fundar un derecho de lo común y la tercera articula 
nueve propuestas políticas para imaginar una organización social y política a través del autogobierno.

\section{¿Qué es lo común?}

En los cinco primeros capítulos, los autores invocan la pertinencia de inventar un concepto nuevo, pero acudiendo al pasado. Laval y Dardot recuperan de la etimología de la palabra común su raíz latina munus que designa un oficio o tarea pública. Todas las palabras que comparten esta raíz remiten a un significado de puesta en común de cargos o tareas. De ahí coligen que lo común supone una coobligación de personas comprometidas en una misma actividad pública. Esa es una primera clave para entender lo común como un principio político, como sustantivo y no como adjetivo y que "debe ser pensado como una coactividad, no como una copertenencia, copropiedad o coposesión” (p. 37). Así, rechazan que lo común se equipare al comunismo de Estado. Describen tres concepciones históricas del comunismo: la primera remitía a la comunidad y sus valores de igualdad; la segunda, definida por Marx, se refiere a la autoorganización de la sociedad de acuerdo con las fuerzas y facultades de sus miembros; y la tercera es la de los Estados comunistas que a través de un partido controlaban la riqueza y el poder social. Esta última forma de comunismo terminaría revelándose como el rostro "de un Estado terrorista que acaparó no sólo el monopolio de la violencia arbitraria, sino también el monopolio del discurso sobre el mundo social, el pensamiento, el arte y la cultura, así como sobre el porvenir de las sociedades" (p. 92). Este monopolio de lo común por el Estado significó su destrucción. En consecuencia lo común no debe concebirse como un "origen a restaurar, ni considerarse dado inmediatamente en el proceso de producción, ni impuesto exteriormente, desde arriba" (p. 107). Los autores exponen dos modelos para entender lo común: el de Marx, en el que lo común se produce a partir de las relaciones de cooperación entre obreros, y el de Proudhon, en el que la relación social es la que genera riqueza colectiva. Concluyen que hay que inventar otro modelo teórico de lo común que dé cuenta de las prácticas colectivas y de las luchas políticas.

\section{Un derecho de lo común}

La inquietud por otro modelo teórico sobre lo común conduce a la segunda parte del libro "Derecho e institución de lo común", compuesta por cinco capítulos. Aquí sostienen la tesis de que lo común debe instituirse como 
inapropiable. Aristóteles distingue dos tipos de "puesta en común": la de todos los bienes (que sería impracticable) y la de las palabras, los pensamientos y las acciones. La segunda puesta en común es inapropiable porque no es un bien que se puede adquirir, comprar o intercambiar. Este intercambio de palabras presupone la definición de lo justo y hace posible la existencia de una comunidad política. La justicia entonces no procede de un orden político establecido sino de la actividad de deliberación y puesta en común. Para pertenecer a una comunidad política hay que comunicarse, poner en común y participar: "la pertenencia es la consecuencia, no la causa, de la participación" (p. 269). Por tanto, la única política capaz de retomar el sentido de la palabra griega koinonein, que significa "poner en común", sería aquella que convierte lo común en su objeto, principio y centro.

Lo común debe instituirse a través del derecho. ¿Cuál sería este derecho?, ¿de dónde vendría su fundamento? Los autores concluyen que la Common Law, el derecho consuetudinario de la pobreza y el derecho proletario aportan un fundamento para tal derecho. Proudhon, "uno de los primeros teóricos de la institución de lo común" (p. 419), plantea una alternativa a la propiedad privada e impele a los obreros a crear "nuevas formas de institución" (p. 420) que se construirían desde abajo a partir de la interacción social. Se trataría de un derecho social creado a partir de la sociedad y no uno creado o dictado por legisladores: "así el derecho está destinado a devolver a la sociedad la plena posesión de su fuerza colectiva. Esta recuperación es el verdadero objetivo que debe perseguir el movimiento social" (p. 421). Un nuevo derecho no saldría de la nada, sino de las prácticas sociales, se construiría sobre las ruinas del derecho romano que separa derecho público y privado, funcionaría con contratos y acuerdos entre la sociedad. Se diferenciaría del liberalismo en que los contratos serían el resultado de relaciones sociales basadas en el verdadero valor del trabajo, en la equidad y en el principio de mutualismo que se traduce en beneficios justos (p. 426). El fundamento del derecho de lo común provendría de la constitución social definida como "la autoorganización jurídica de la sociedad que, partiendo de la constatación de los derechos particulares de las diferentes agrupaciones, hace de todo ello un derecho común formalizado de los coproductores de toda la sociedad" (p. 426). El derecho social se fundaría en la experiencia, en las acciones y en las relaciones sociales y económicas.

Laval y Dardot postulan entonces que es necesario establecer un derecho de inapropiabilidad que se oponga al derecho de propiedad. Se trata de una inversión del método: "inventar reglas de derecho capaces de convertirse a la larga en costumbres" (p. 460), pues nadie puede decretar una costumbre, pero sí es posible a través de la práctica colectiva establecer reglas. A esto llaman la "praxis instituyente", de ahí que el significado de institución merezca una re- 
visión. Desde la sociología primó su asimilación como "conjunto de actos instituidos", sin embargo, esta comprensión dejaba de lado la institución como acción de instituir. Si la institución es algo que ya está dado y solo es cuestión de transmitir sus reglas, se sacrifica la dinámica por la estática. Para Cornelius Castoriadis no es la modificación o transformación de lo instituido lo que produce el cambio sino lo nuevo mismo y eso nuevo puede producirse a partir de la nada y a través de lo imaginario: "contra la reducción sociológica de la institución a lo instituido, Castoriadis hace valer la primacía de lo instituyente sobre lo instituido: el segundo nunca es más que el resultado del ejercicio del poder instituyente como poder de creación" (p. 477). De esta manera, la emancipación surge de una sociedad instituyente y la historia se da a partir de lo no causal o la "novedad radical" (p. 480), y no de la causalidad como lo ha explicado la sociología. Laval y Dardot tienen en cuenta la condición ineludible de que cualquier creación de los hombres está determinada por las condiciones existentes y las generaciones anteriores, pero esto es precisamente lo que hace posible el cambio, ya que estas condiciones no son inmodificables. Entonces la "praxis instituyente" haría posible el surgimiento de nuevas reglas de derecho a través de la creación de instituciones y de una actividad continuada que permita repensar la institución para evitar que se convierta en instituida. Esta praxis no solo crea reglas sino que produce un sujeto colectivo a partir de "un ejercicio que hay que renovar sin cesar más allá del acto creador” (p. 505).

\section{Autogobierno de lo común}

La última parte del libro presenta nueve propuestas políticas y una conclusión sobre la revolución en el siglo XXI. Las luchas, movimientos y prácticas sociales tienen el reto de crear nuevas instituciones con la doble característica de oponerse al capitalismo, al comunismo de Estado y desarrollar una forma de autogobierno. Estas nuevas instituciones no surgen de fórmulas o teorías preconcebidas sino de la experimentación y de la imaginación. Sus propuestas políticas, como ellos mismos lo advierten, son un acto de imaginación. Las primeras dos enuncian la necesidad de construir una política de lo común que conciba "una nueva institución de los poderes en la sociedad" (p. 519) y que organice lo común en instituciones y sistemas de autogobierno. Proponen que en todos los ámbitos donde los seres humanos actúan y toman decisiones pueden definir las reglas y formas de actuar. Este modelo federativo se organizaría bajo el principio de la cooperación y el autogobierno, debería ser transversal a lo local, lo nacional y lo global. Esto implica someter el derecho absoluto de la propiedad al derecho de uso y de inapropiabilidad como "el eje de la 
transformación social y política" (p. 524). El derecho de uso no sería equiparable al derecho que tiene lugar en un marco capitalista en que unos pocos poseen la propiedad y determinan las condiciones de acceso. Por el contrario, el derecho de uso e inapropiabilidad iría aparejado con la coproducción de reglas. Para explicar cómo funcionaría refieren la experiencia de Vandana Shiva y la gestión colectiva de semillas que son resguardadas, cuidadas y usadas por las comunidades, pensando en su uso y beneficio para el consumo de alimentos y no para el lucro. El banco de semillas que Shiva puso en marcha con comunidades campesinas va en contra del derecho de propiedad que privatiza las semillas a través de patentes.

La tercera, cuarta y quinta propuestas están dirigidas a la modificación de las condiciones de trabajo. Plantean anteponer una alternativa al trabajo individualizado y de competencia que impone la empresa donde la colaboración no deja de ser un discurso del management. El trabajo debería estar orientado a la recuperación de los vínculos, la solidaridad, el verdadero actuar en común que recobre la "finalidad social de toda actividad laboral", esto sería posible pensando la empresa como una "institución democrática" (p. 555). La pregunta es cómo instituir una empresa común. La empresa como institución democrática se lograría mediante la gestión cooperativa, de ahí la necesidad de no construir una economía social separada de otra economía de mercado. La economía tendría que ser toda social, tener en cuenta los aportes de la sociedad civil y demostrar que la cooperación además de ser buena socialmente, es más efectiva que la competencia. Laval y Dardot proponen la creación de organizaciones cooperativas y autogestionadas que formen un modelo de oposición y de construcción económica: "la sociedad futura también debería basarse ni más ni menos que en la economía de mercado, en un principio de libertad económica. Pero en este caso la libertad será para todos y no solo para los poseedores de capitales" (p. 573).

Las últimas cuatro propuestas esbozan el orden que podría tener esta sociedad basada en lo común. Formulan la fundación de una democracia social que devuelva a la sociedad el control de las instituciones democráticas confiscadas por un Estado que se ha dedicado a poner las instituciones y recursos públicos al servicio del mercado a través del discurso de austeridad. Abogan por la conversión de los servicios públicos en instituciones de lo común, gobernadas democráticamente por organizaciones de ciudadanos y usuarios con la participación del gobierno y la premisa de servir a las necesidades colectivas. Exponen el caso de la remunicipalización del agua en Nápoles, que tras un referendo en 2011 decidió que el agua se administraría de forma colectiva y no a través de empresas privadas. Esta democracia social también debe replantear el papel de los organismos internacionales que actúan en alianza con oligopolios. Habría que cuestionar el discurso de estos organismos internacionales que equiparan derechos fundamen- 
tales a "bienes", lo que evidencia que "la lógica de los mercados se dirige contra la lógica de los derechos fundamentales" (p. 618). Se trata entonces de componer "un derecho superior a las soberanías públicas y privadas y a los derechos de propiedad" (p. 617). En consecuencia, una práctica emancipadora no solo debe preocuparse por defender bienes sino por crear instituciones alternativas, por construir un nuevo poder sin ceder en la toma del poder. El final del libro recapitula diez conclusiones que enfatizan en que lo común es el corazón del proyecto revolucionario. Común se inserta en el debate contemporáneo sobre las posibilidades de tránsito desde el neoliberalismo a otra racionalidad. Es un punto de partida que no solo cuestiona las concepciones de lo público, de lo privado y del derecho a la propiedad; sino que otorga a lo común un fundamento filosófico, jurídico y político para revelarlo como un principio nuevo, capaz de dar forma al reto colectivo de contener y reversar los cercamientos y privatizaciones que amenazan la vida.

\section{Lina Marcela Marín Moreno*}

* Periodista y Máster en Políticas Sociales. Estudiante del Doctorado en Estudios Interdisciplinarios sobre Pensamiento Cultura y Sociedad de la Universidad de Valparaíso (con financiamiento del CONICYT-PFCHa. Doctorado Nacional 2017/Folio 21170677) y del Doctorado en Ciencias Sociales de la Universidad de Salamanca. 